\title{
Recognition, Investigation and Management of Mitochondrial Disease
}

James E Davison ${ }^{1}$ and Shamima Rahman ${ }^{1,2}$

1. Metabolic Unit, Great Ormond Street Hospital for Children NHS Foundation Trust, London, UK.

2. Mitochondrial Research Group, UCL Great Ormond Street Institute of Child Health, London, UK.

\section{Correspondence:}

Prof Shamima Rahman

Mitochondrial Research Group, UCL Great Ormond Street Institute of Child Health, London WC1N 1EH, UK.

Telephone: 02079052608

Email: shamima.rahman@ucl.ac.uk

Word count: main text 3546

\section{Key words:}

Mitochondrial disease; clinical phenotypes; diagnosis; next generation sequencing; treatment 


\section{Summary}

Mitochondria are dynamic organelles present in virtually all human cells that are needed for a multitude of cellular functions, including energy production, control of cell apoptosis and numerous biochemical catabolic and synthetic pathways that are critical for cellular health.

Primary mitochondrial disorders are a group of greater than 200 single gene defects arising from two genomes (nuclear and mitochondrial) leading to mitochondrial dysfunction, and are associated with extremely heterogeneous phenotypes. Neuromuscular features predominate, but often with multisystem involvement.

Clinical suspicion of a mitochondrial disorder should prompt multi-pronged investigation with biochemical and molecular genetic studies. Recent wide scale adoption of next generation sequencing approaches has led to a rapid increase in the number of disease genes.

The advances in unravelling the genetic landscape of mitochondrial diseases have not yet been matched by progress in developing effective therapies, and the mainstay of care remains supportive therapies in a multidisciplinary team setting. 


\section{Mitochondrial physiology and genetics}

The mitochondrion is an ubiquitous and dynamic cellular organelle with many fundamental roles in maintaining normal cellular function. Since the mitochondrion was first described in the late $19^{\text {th }}$ century by Altmann and Benda,[1] our understanding of the complexities of mitochondrial function, maintenance and replication, and the often catastrophic implications of mitochondrial dysfunction, has greatly advanced.

Mitochondria are composed of a cardiolipin-containing double membrane, with the outer mitochondrial membrane surrounding the highly convoluted inner mitochondrial membrane. The five protein multi-complexes of the respiratory chain are embedded in the inner membrane, while the mitochondrial matrix contains the enzymes of numerous associated metabolic pathways including the tricarboxylic acid (TCA) cycle, part of the urea cycle and the machinery of fatty acid beta-oxidation. Complexes I-IV of the respiratory chain/electron transport chain use the reducing potential of $\mathrm{NADH}$ and $\mathrm{FADH}_{2}$ generated by glycolysis, the TCA cycle and fatty acid oxidation to pump protons into the inter-membrane space, thereby generating an electrochemical gradient which complex $\mathrm{V}$ dissipates to facilitate the phosphorylation of adenosine diphosphate to generate adenosine triphosphate (ATP), the fundamental "energy currency" of the cell. In addition to energy production, control of cell apoptosis and numerous biochemical synthetic pathways are crucial mitochondrial functions that also contribute to the pathophysiology when mitochondrial function is deranged.

Mitochondrial proteins are encoded in genes held in the nuclear DNA and also in the mitochondrial DNA (mtDNA). mtDNA is a small 37-gene, $16.5 \mathrm{~kb}$ DNA molecule found in multiple copies within the mitochondrial matrix.[2] Together, the nuclear and mitochondrial genomes encode more than 1500 proteins involved in mitochondrial structure and function,[3] including several nuclear genes that encode machinery important in the replication and maintenance of the mtDNA.[4]

Primary mitochondrial diseases are known to be caused by mutations in more than 200 of the nuclear genes (figure 1a), inherited in Mendelian patterns (autosomal recessive, autosomal dominant or X-linked), and all the 37 mtDNA encoded genes (figure 1b).[5] As mtDNA is only acquired from the maternal gamete (ovum) at conception, mtDNA mutations are maternally inherited, or may be sporadic de novo events.

MtDNA has a high copy number (hundreds or thousands of copies per cell) and normal and mutated mtDNA often coexist in the same cell, a phenomenon called heteroplasmy. Problems only arise if the proportion of mtDNA that is mutated exceeds a threshold. As the level of mutant mtDNA varies 
between individuals and between tissues in any one individual, different patients with the same mtDNA mutation can have very different symptoms

\section{Recognition of Mitochondrial Disease}

Mitochondrial disorders are thought to affect around 1:5000 of the population.[6] There is a wide heterogeneity in the clinical phenotype, with involvement of either single or multiple organ systems and the consequent clinical features (table 1). The age of presentation also varies widely, ranging from neonatal onset with fulminant lactic acidosis, to relatively mild disease in old age.

Highly energetic tissues including skeletal muscle and nervous system are the most commonly affected due to their greater reliance on mitochondrial ATP synthesis. However, any organ system can be affected and one of the "red flags" alerting clinicians to the potential for a mitochondrial disorder is the association of neurological or muscular symptoms with concurrent or subsequent multi-organ involvement. The occurrence of muscle or central nervous system disease with involvement of two or more other organ systems, or any combination of disease affecting three or more organ systems should prompt consideration of mitochondrial disease. The multitude of potential presenting features means that mitochondrial diseases may be encountered by numerous medical specialists.

Mitochondrial diseases are also progressive, with fluctuation and deterioration expected over time, with the potential for additional organ systems to be involved as time progresses. Progressive involvement of neuromuscular symptoms will often present with neurological regression in the developing child, and progressive loss of skills at any age.

\section{Phenotypic syndromes}

Certain clinically distinct clusters of symptoms and features are recognised as phenotypic mitochondrial syndromes. Recognition of a mitochondrial syndrome can lead directly to a specific genetic diagnosis. It is, however, well recognised that the same genetic mutation or deletion can give rise to varied phenotypes, and conversely certain phenotypes can be caused by mutations in a range of different genes.

Leigh syndrome and Leigh-like syndrome are infantile onset mitochondrial encephalopathies associated with bilateral symmetrical brain lesions particularly affecting the basal ganglia, thalamus 
and brain stem. Affected individuals usually present in the first year of life with developmental regression, respiratory abnormalities, feeding difficulties and frequently with ophthalmic involvement (nystagmus, retinal dysfunction, ophthalmoplegia).[7,8] The genetic basis of these disorders is diverse, encompassing both nuclear and mtDNA mutations involving at least 89 different genes.[9] Originally a post mortem pathological diagnosis, typical in vivo MRI patterns are now the cornerstone of diagnosis of Leigh syndrome.

Alpers disease is defined by progressive neurodegeneration, refractory seizures and liver dysfunction. It is usually caused by mutations in the nuclear gene POLG which encodes the catalytic subunit of DNA polymerase gamma (pol $\gamma$ ) which is required for the correct replication of mtDNA.[10] Dysfunction of pol $\gamma$ leads to progressive depletion of mtDNA with subsequent mitochondrial dysfunction. Valproate toxicity is well recognised and this should be avoided in patients with this diagnosis.

Mitochondrial Recessive Ataxia Syndrome (MIRAS) is one of the ataxia neuropathy spectrum disorders also caused by specific mutations in POLG.[11] This group of disorders is characterised by ataxia and neuropathy, variably associated with an encephalopathy with seizures.

MELAS syndrome is the combination of mitochondrial Myopathy, Encephalopathy, Lactic Acidosis and Stroke-like episodes, with the majority of cases being caused by a common mtDNA mutation ( $m .3243 A>G$ ) in the mtDNA gene encoding a mitochondrial leucine transfer RNA (tRNA).[12] Strokelike episodes are typically heralded by migraine headache, vomiting and seizures. Other clinical features include cognitive decline, ataxia, deafness, optic atrophy, short stature, diabetes and hypertrophic cardiomyopathy. The vast majority of individuals with the m.3243A $>$ G mutation never develop strokes and have other clinical problems, most commonly maternally inherited diabetes and deafness.[13]

MERRF describes the phenotype of Myoclonic Epilepsy and Ragged Red Fibres, the latter being a histopathological description of the appearances on muscle biopsy. MERRF is often caused by a mutation in the mtDNA gene encoding the tRNA for lysine, and is one of the disorders specifically associated with epilepsy phenotypes, often with ataxia.[14] Some patients have additional visual, audiological and cardiac involvement.

Pearson syndrome is comprised of infantile onset sideroblastic anaemia (often transfusion dependent), lactic acidosis and variable pancreatic exocrine dysfunction.[15] It is associated with a sporadic large deletion in the mtDNA. Many infants do not survive and succumb to liver failure or 
overwhelming acidosis in the first few years of life, but those who do live beyond infancy inevitably develop features of the Kearns-Sayre Syndrome.[16]

Kearns-Sayre Syndrome (KSS), also caused by a large mtDNA deletion, may follow Pearson syndrome or present later without preceding anaemia, with onset before 20 years of age with ptosis, progressive external ophthalmoplegia (PEO) and pigmentary retinopathy.[17] Cardiac conduction defects, cerebellar ataxia and cerebral folate deficiency are other features.[16]

Progressive External Ophthalmoplegia (PEO) is a feature of several disorders or can occur in isolation, and is often associated with mtDNA deletions, which may be single (sporadic) or multiple (secondary to autosomal dominant or recessive nuclear gene mutations).

Leber hereditary optic neuropathy (LHON) occurs due to specific mtDNA mutations giving rise in adolescence or adult life to painless visual loss, usually an isolated phenomenon affecting both eyes sequentially.

Neuropathy, Ataxia, Retinitis Pigmentosa (NARP) is often due to mutations in the mtDNA gene MTATP6 encoding a subunit of ATP synthase. Individuals with high loads of the same mutations (typically >90\%) present with maternally inherited Leigh syndrome.

Mitochondrial Neuro-Gastro-Intestinal Encephalopathy (MNGIE) presents with gastrointestinal dysmotility, peripheral neuropathy and eye involvement, and is caused by mutations in the nuclear gene TYMP that encodes thymidine phosphorylase.[18] This results in a mtDNA depletion syndrome. The enzyme deficiency results in abnormal blood and urinary thymidine and deoxyuridine concentrations, and so blood/urine purine/pyrimidine analysis can suggest the diagnosis.

Myopathy, Lactic Acidosis and Sideroblastic Anaemia (MLASA) is a rare autosomal recessive disorder predominantly affecting the skeletal musculature and bone marrow. It is usually caused by a defect of the YARS2 mitochondrial aminoacyl tRNA-synthetase or the PUS1 tRNA pseudouridinylation enzyme, both of which are involved in mitochondrial translation.[19]

\section{Reversible Disorders}

While most mitochondrial disorders are considered progressive, a small number display a reversible phenotype. Such disorders include the infantile reversible myopathy due to the mtDNA mutation m.14674T >C/G in the MT-TE gene encoding the tRNA for glutamate, and reversible infantile liver disease due to mutations in TRMU encoding an enzyme that functions in normal mitochondrial tRNA modification.[20] Prompt recognition of these rare reversible disorders may enable the appropriate 
continuation of supportive treatment (such as prolonged ventilation) with the anticipation of subsequent recovery.

\section{Investigation of Mitochondrial Disease}

If a mitochondrial disorder is suspected, investigations aim firstly to provide additional evidence (clinical, biochemical, radiological) for mitochondrial disease, then secondly attempt to identify a specific genetic basis for the disease, and thirdly to evaluate for multi-system effects and in particular to detect treatable complications. In practice these three aims are addressed simultaneously.

\section{Multi-system evaluation}

Careful clinical evaluation may reveal multi-system dysfunction, and if signs or symptoms become evident specific investigations will be warranted. Table 2 includes examples of investigations that may be indicated in clinical baseline evaluation and on-going monitoring.

\section{Specific Metabolic Biochemistry}

Lactate may be elevated in blood and cerebrospinal fluid in mitochondrial disorders, but normal lactate levels do not exclude the possibility of a mitochondrial disorder. Measurement of lactate preand post-prandially can be useful in distinguishing mitochondrial disorders from disorders affecting glycogen metabolism. Lactate is the end product of anaerobic respiration (glycolysis), being reversibly converted from pyruvate by lactate dehydrogenase (LDH). Dysfunction of the respiratory chain results in impaired aerobic respiration, while the ratio of $\mathrm{NADH}$ to $\mathrm{NAD}^{+}$(reflecting the abnormal mitochondrial redox status) is increased, driving the production of lactate. Measurement of the lactate/pyruvate ratio can help distinguish respiratory chain dysfunction from defects in earlier steps in pyruvate metabolism, notably pyruvate dehydrogenase deficiency. Lactate may be artefactually increased if a blood sample is difficult to obtain. Lactate may be increased secondary to tissue hypoxia of any cause including sepsis or significant hypotension. Neonatal lactic acidosis is common after a hypoxic-ischaemic insult, but would be expected to normalise over a few days. Elevated CSF lactate is also seen in non-mitochondrial brain diseases such as encephalitis, however an elevated CSF lactate without evidence of an alternative brain insult or recent seizures is 
suspicious for mitochondrial disease. The same applies to lactate detected non-invasively by magnetic resonance spectroscopy of the brain.

Plasma amino acids may show an elevated alanine concentration, again reflecting chronically increased pyruvate and lactate levels. Proline may also be elevated, while decreased citrulline may be seen in MELAS and NARP syndromes.[21,22]

Plasma acylcarnitines may be helpful in differentiating from other causes of lactic acidosis, including long chain fatty acid oxidation defects and organic acidaemias, and may also identify specific metabolites in disorders of flavin metabolism and disorders causing toxic damage to the respiratory chain, such as ethylmalonic acidaemia and HIBCH and ECHS1 deficiencies.[23,24]

Urine organic acid analysis may reveal elevated lactate and associated metabolites; intermediates of the TCA cycle, and ethylmalonic acid, may be seen as a non-specific indicator of mitochondrial dysfunction. 3-methylglutaconic aciduria is seen in a range of disorders including Barth syndrome.[25] Methylmalonic aciduria may be seen in SUCLA2 deficiency and related disorders.[26] Biotinidase activity detects biotinidase deficiency, which should be ruled out as this is easily treated with biotin supplementation, and is included in routine newborn screening in some countries.

Novel biomarkers that have been reported to be elevated in mitochondrial disease include fibroblast growth factor 21 (FGF21) and growth and differentiation factor 15 (GDF15), but these are neither specific for mitochondrial disease nor are they elevated in all cases.[27,28]

\section{Neuroimaging}

Magnetic resonance imaging (MRI) is a powerful tool for evaluating brain involvement. Brain imaging may be undertaken during the investigation of a child with developmental issues, seizures or for other reasons, and certain features may give rise to the suspicion of mitochondrial disease. The central nervous system features seen in neuroradiological examination of mitochondrial disorders are diverse (figure 2). Typical features of Leigh syndrome include bilateral symmetrical signal abnormality in the basal ganglia (figure $2 \mathrm{~b}$ ) and brain stem. White matter may be diffusely abnormal (leukodystrophy) in a number of mitochondrial disorders including complex I (figure 2a) and complex II deficiency;[29] there can be non-specific cerebral atrophy; progressive cerebellar atrophy may be seen in mitochondrial disease but is not specific for this. Specific patterns of brain involvement may be associated with specific genotypes, including leukoecenphalopathy with brainstem and spinal cord involvement with elevated lactate (LBSL, associated with DARS2 mutations).[30] Infarcts that 
do not correspond to an arterial territory are a hallmark of MELAS syndrome (figure $2 c, d$ ).[12] Structural brain abnormalities may be seen for example in pyruvate dehydrogenase complex (PDH) deficiency.[31]

\section{Muscle Biopsy}

Historically a muscle biopsy (either open surgical, or with large-bore needle biopsy) for histopathological tests and functional enzyme assays has been an important investigation for suspected mitochondrial diseases, although more recently the advent of more rapid genetic testing with next generation sequencing has superseded the need for a muscle biopsy in some situations. However a muscle biopsy may be helpful in differentiating from other causes of myopathy.

\section{Histochemistry}

Histochemical findings can be suggestive of mitochondrial disease, including the detection of ragged red fibres on the modified Gomori trichrome stain, or the observation of cytochrome $c$ oxidasenegative fibres. Non-specific findings include excess lipid deposition and mitochondrial ultrastructural changes on electron microscopic examination. Recently, a modified immunohistochemical technique known as quadruple OXPHOS immunofluorescence has been reported to provide more quantitative data about oxidative phosphorylation function.[32] Occasionally cardiac muscle biopsies undertaken to investigate an unexplained cardiomyopathy reveal features suggestive of mitochondrial disease, including giant mitochondria and abnormal mitochondrial ultrastructural appearances.

\section{Respiratory Chain Enzymology}

Spectrophotometric assays of complexes I-IV in a frozen muscle homogenate assess the function of the respiratory chain complexes and can identify either multiple or isolated complex deficiencies. Combined assay of complexes I+III or II+III indirectly assesses muscle coenzyme $\mathrm{Q}_{10}\left(\mathrm{CoQ}_{10}\right)$ which shuttles electrons between these two complexes, and muscle $\mathrm{CoQ}_{10}$ can also be quantified directly. Complex $\mathrm{V}$ can be assayed by Polarographic analysis of fresh muscle mitochondria or by Blue native gel assay of frozen muscle homogenate.

Isolated complex deficiencies (e.g. of complex I) are often caused by mutations in a gene encoding either one of the structural subunits of the complex or an associated assembly factor, and identification of a specific isolated complex deficiency can help direct further targeted genetic analysis. 
Mitochondrial DNA depletion syndromes are caused by nuclear gene defects affecting genes responsible for the maintenance and replication of the mIDNA, including POLG,TK2, RRM2B and DGUOK (figure 1a). These result in multiple deficiencies of the respiratory chain complexes. Similarly, disorders affecting mitochondrial DNA transcription or translation can result in multiple complex deficiencies. Since complex II is entirely encoded by nuclear genes it is not primarily affected in disorders of mtDNA (although complex II activity may be decreased secondarily if the muscle is severely compromised).

A skin biopsy may be obtained either as a punch biopsy or at the time of an open muscle biopsy, to obtain cultured fibroblasts. These can be used to assess oxidative phosphorylation function, e.g. by microscale oxygraphy, or to assay PDH and pyruvate carboxylase activity; PDH can also be assayed in the muscle sample.[31]

It should be noted that muscle respiratory chain enzymology may be normal in a patient with genetically confirmed mitochondrial disease, for example where the tissue-specific phenotype does not involve muscle.

\section{Molecular Genetics}

The constellation of features from the clinical history, examination and results of initial biochemical and radiological investigations can direct analysis to specific candidate genes (e.g. screening for specific mtDNA mutations in MELAS, LHON or NARP syndromes, or for POLG mutations in Alpers syndrome). Particular patterns of respiratory chain enzyme complex deficiencies on muscle biopsy can also suggest groups of genes to be evaluated. The family history can suggest whether a nuclear gene defect (in a consanguineous family with multiple affected individuals on both sides of the pedigree) or a mtDNA defect (matrilineal pattern of inheritance) is more likely.

Nuclear genes can be assessed with DNA extracted from blood. mtDNA mutation load varies from tissue to tissue, with highest levels of mutation heteroplasmy expected in affected tissues, and as a result mtDNA analysis is best performed on DNA extracted from an affected tissue, usually muscle DNA. However, in infants with severe mtDNA-encoded disease it is expected that the blood heteroplasmy level will be sufficiently high that analysis of blood DNA will detect mtDNA mutations. mtDNA analysis may start with analysis for large scale deletions or rearrangements, followed by specific common point mutation analysis, and finally full mtDNA sequencing. Individual candidate nuclear genes can be Sanger-sequenced directly. However the genetic complexity underlying 
mitochondrial disease, with hundreds of candidate genes, means that this is an inefficient approach and increasingly next generation sequencing is being employed to evaluate larger panels of genes or whole exomes or genomes. Furthermore, as we move away from muscle biopsies as the gold standard diagnostic test, novel bioinformatics tools will be needed to help confirm pathogenicity of observed genetic variants.[9]

Parental blood DNA samples are required to evaluate nuclear gene mutations identified in the proband; DNA samples from blood and urinary cellular sediments from the mother may be evaluated in the case of mtDNA encoded disorders to determine maternal levels of mtDNA mutation heteroplasmy. Subsequently it may be appropriate to undertake cascade family screening. Identification of the mode of inheritance can also help inform discussions about recurrence risk for future children and potential reproductive options. Involvement of clinical genetics teams is important.

\section{Management of mitochondrial disorders}

The management of a child with mitochondrial disease requires the input of many different healthcare professionals (including metabolic physicians, neurologists, cardiologists, endocrinologists, gastroenterologists, nephrologists, intensivists, ophthalmologists, audiological physicians, community paediatricians, dietitians, nurses, physiotherapists, speech and language therapists and psychologists) collaborating to optimise clinical management, addressing the numerous complications that arise. Ensuring good nutrition, monitoring growth and developmental parameters, providing appropriate support for education and physical mobility needs are all critical aspects of management.

General supportive interventions need to be tailored according to the patient-specific problems that arise, and can span numerous medical specialities (Table 3). Some invasive interventions such as solid organ transplantation may not be considered appropriate in the context of progressive multisystem disease, but may be considered if there is an isolated single-organ failure in limited circumstances. 


\section{Specific therapies}

There is also a growing evidence base for specific therapies for mitochondrial disorders,[33] although the challenges of undertaking rigorous randomised controlled trials in such disparate and rare disorders is reflected in the relatively small number of high quality trials identified by the Cochrane review process.[34]

\section{Lactic acidosis}

Lactic acidaemia if severe can result in acidosis; in such situations appropriate use of sodium bicarbonate to normalise acid-base status is required. Dichloroacetate stimulates PDH activity by inhibition of PDH kinase and can decrease lactate levels. However, the impact on long term outcome is not clear, and long term use may be associated with peripheral nerve toxicity.[34,35]

\section{Treatable disorders}

There is a small group of readily treated disorders that respond to specific therapies, and these should be identified promptly and treatment initiated in a timely manner.[5] These include use of $\mathrm{CoQ}_{10}$ supplements for $\mathrm{CoQ}_{10}$ biosynthesis defects; riboflavin (vitamin B2) in riboflavin-responsive disorders such as ACAD9 or FLAD1 deficiency;[36,37] biotin in biotinidase deficiency; and combinations of biotin and thiamine in high doses for biotin-thiamine responsive basal ganglia disease.[38,39]. Thiamine is given if PDH deficiency is suspected as some defects are thiamine responsive. A deficiency of 5-methyltetrahydrofolate (the major transport form of folic acid) has been reported in a several mitochondrial disorders including KSS and is treatable with regular folinic acid. Supplementation with these therapies may be initiated empirically while awaiting final diagnostic investigations.

\section{Arginine in MELAS syndrome}

There is growing evidence for the use of arginine therapy in MELAS syndrome for both acute treatment and prevention of stroke-like episodes.[12] Arginine is required for nitric oxide synthesis, and the observation of low arginine and citrulline levels in patients particularly during acute stroke episodes supports the hypothesis that vasodysregulation contributes to the aetiology of the strokelike episodes. 


\section{Potentially detrimental drugs}

Certain drugs have the potential to be detrimental in the context of a mitochondrial disorder and should be avoided or used with caution.[40] These include sodium valproate (risk of hepatotoxicity, and contra-indicated in patients with POLG mutations), and anaesthetic agents such as propofol.[41]

\section{Novel therapies under evaluation}

\section{Antioxidant therapy}

Excessive production of reactive oxygen species occurs when the respiratory chain is dysfunctional, and it is thought that consequent oxidative stress may play an important role in the pathophysiology of mitochondrial disorders.[35] Numerous antioxidants have been used in the treatment of mitochondrial diseases. Therapies include $\mathrm{CoQ}_{10},[42]$ and the related compounds idebenone [33] and EPI-743.[43] N-acetylcysteine is a cysteine donor and can replenish glutathione, although evidence for therapeutic efficacy is lacking. Vitamin C, E and chemical analogues are also being evaluated.

\section{Stimulating mitochondrial biogenesis}

Approaches aimed at increasing mitochondrial biogenesis have been evaluated, using both pharmacological approaches such as bezafibrate (a PPAR $\alpha$ activator) or resveratrol (a SIRT1 sirtuin activator) as well as dietary approaches via the ketogenic diet, which all result in up-regulation of mitochondrial gene expression and subsequent mitochondrial biogenesis.[35] Recently, decanoic acid, a C10 fatty acid produced in response to the ketogenic diet, has been found in vitro to stimulate mitochondrial biogenesis,[44] and may have efficacy in primary mitochondrial disease although formal clinical trials are still needed.[45]

\section{Other novel therapies}

Other novel therapeutic approaches include: targeting the mitochondrial membrane and its complex lipids;[46] replacing nucleosides in mtDNA depletion disorders that are associated with nucleoside deficiency; [47] and gene therapy approaches including recoding mtDNA-encoded genes to be expressed in the nuclear genome (allotopic gene expression), "conventional" viral-vector mediated nuclear-targeted gene therapies, and selective destruction of mutant mtDNA using restriction endonuclease technologies (see [5]). 


\section{Future reproductive options}

While detailed comment is beyond the scope of this review, parents of a child with mitochondrial disease, or who are known carriers of either nuclear or mitochondrial gene mutations, may consider a number of options for future children, including antenatal testing, pre-implantation genetic diagnosis [48] or potentially "mitochondrial donation" technologies [49] although these methods have generated medical ethical debate.

\section{Conclusions}

Understanding of normal mitochondrial physiology has been furthered through the insights gained from the clinical and laboratory investigation of patients with diverse mitochondrial genetic disorders. Early consideration of the possibility of a mitochondrial disorder, followed by careful clinical assessment and biochemical, radiological and genetic investigation can lead to a diagnosis of mitochondrial disease. Diagnosis will then prompt symptomatic, and in some situations, disease modifying, therapies. Novel therapies in the pipeline aim to further improve the prognosis for children affected by these frequently devastating disorders.

\section{Acknowledgements}

SR is supported by a Great Ormond Street Hospital Children's Charity Research Leadership Award (V1260) and her group currently receives research grant funding from the Lily Foundation and the National Institute for Health Research Biomedical Research Centre at Great Ormond Street Hospital for Children NHS Foundation Trust and University College London. 


\section{References}

\begin{tabular}{|c|c|}
\hline [1] & Ernster L, Schatz G. Mitochondria: a historical review. J Cell Biol 1981;91:227s-255s. \\
\hline [2] & $\begin{array}{l}\text { Chinnery PF. Mitochondrial Disorders Overview. In: Pagon RA, Adam MP, Ardinger } \\
\text { HH, et al, eds. GeneReviews [Internet]. Seattle (WA): University of Washington, } \\
\text { Seattle; 1993-2017. }\end{array}$ \\
\hline [3] & $\begin{array}{l}\text { Cohen BH. Mitochondrial Medicine. In: Saneto RP, Parikh S, Cohen BH, eds. } \\
\text { Mitochondrial Case Studies: Underlying mechanisms and diagnosis. London. } \\
\text { Elsevier 2016:1-9. }\end{array}$ \\
\hline [4] & $\begin{array}{l}\text { Calvo SE, Clauser KR, Mootha VK. MitoCarta2.0: an updated inventory of } \\
\text { mammalian mitochondrial proteins. Nucleic Acids Res 2016;44(Database issue): } \\
\text { D1251-D1257. }\end{array}$ \\
\hline [5] & $\begin{array}{l}\text { Rahman S. Emerging aspects of treatment in mitochondrial disorders. J Inherit } \\
\text { Metab Dis 2015;38:641-653. }\end{array}$ \\
\hline [6] & $\begin{array}{l}\text { Thorburn DR. Mitochondrial disorders: prevalence, myths and advances. J Inherit } \\
\text { Metab Dis 2004;27:349-362. }\end{array}$ \\
\hline [7] & $\begin{array}{l}\text { Davison JE, Rahman S. Nuclear genetic causes of Leigh and Leigh-like syndrome. In: } \\
\text { Saneto RP, Parikh S, Cohen BH, eds. Mitochondrial Case Studies: Underlying } \\
\text { mechanisms and diagnosis. London. Elsevier 2016:113-126. }\end{array}$ \\
\hline [8] & $\begin{array}{l}\text { Lake NJ, Compton AG, Rahman S, et al. Leigh syndrome: One disorder, more than } \\
75 \text { monogenic causes. Ann Neurol 2016;79:190-203. }\end{array}$ \\
\hline [9] & $\begin{array}{l}\text { Rahman J, Noronha A, Thiele I, et al. Leigh map: A novel computational diagnostic } \\
\text { resource for mitochondrial disease. Ann Neurol 2017;81:9-16 }\end{array}$ \\
\hline [10] & $\begin{array}{l}\text { Young MJ, Copeland WC. Human mitochondrial DNA replication machinery and } \\
\text { disease. Curr Opin Genet Dev 2016;38:52-62. }\end{array}$ \\
\hline$[11]$ & $\begin{array}{l}\text { Wong L-JC, Naviaux RK, Brunetti-Pierri N et al. Molecular and Clinical Genetics of } \\
\text { Mitochondrial Diseases Due to POLG Mutations. Hum Mutat 2008; 29: E150-E172. }\end{array}$ \\
\hline [12] & $\begin{array}{l}\text { Koenig MK, Emrick L, Karaa A, et al. Recommendations for the management of } \\
\text { strokelike episodes in patients with mitochondrial encephalomyopathy, lactic } \\
\text { acidosis, and strokelike episodes. JAMA Neurol 2016;73:591-594. }\end{array}$ \\
\hline [13] & $\begin{array}{l}\text { Nesbitt V, Pitceathly RD, Turnbull DM, et al. The UK MRC Mitochondrial Disease } \\
\text { Patient Cohort Study: clinical phenotypes associated with the m.3243A>G } \\
\text { mutation--implications for diagnosis and management. J Neurol Neurosurg } \\
\text { Psychiatry 2013;84:936-8. }\end{array}$ \\
\hline [14] & $\begin{array}{l}\text { Rahman S. Mitochondrial disease and epilepsy. Dev Med Child Neurol 2012;54:397- } \\
406 .\end{array}$ \\
\hline [15] & $\begin{array}{l}\text { Rotig A, Cormier V, Blanche S, et al. Pearson's marrow-pancreas syndrome. A } \\
\text { multisystem mitochondrial disorder in infancy. J Clin Invest 1990;86:1601-8. }\end{array}$ \\
\hline [16] & $\begin{array}{l}\text { Broomfield A, Sweeney MG, Woodward CE et al. Paediatric single mitochondrial } \\
\text { DNA deletion disorders: an overlapping spectrum of disease. J Inherit Metab Dis } \\
2015 ; 38: 445-57 \text {. }\end{array}$ \\
\hline [17] & $\begin{array}{l}\text { Maceluch JA, Niedziela M. The clinical diagnosis and molecular genetics of kearns- } \\
\text { sayre syndrome: a complex mitochondrial encephalomyopathy. Pediatr Endocrinol } \\
\text { Rev 2006; 4:117-137. }\end{array}$ \\
\hline [18] & $\begin{array}{l}\text { Taanman JW, Daras M, Albrecht J, et al. Characterization of a novel TYMP splice site } \\
\text { mutation associated with mitochondrial neurogastrointestinal encephalomyopathy } \\
\text { (MNGIE). Neuromusc Disord 2009;19: 151-154. }\end{array}$ \\
\hline [19] & $\begin{array}{l}\text { Shahni R, Wedatilake } \mathrm{Y} \text {, Cleary MA et al. A distinct mitochondrial myopathy, lactic } \\
\text { acidosis and sideroblastic anemia (MLASA) phenotype associates with YARS2 } \\
\text { mutations. Am J Med Genet A 2013;161A:2334-8. }\end{array}$ \\
\hline
\end{tabular}




\begin{tabular}{|c|c|}
\hline$[20]$ & $\begin{array}{l}\text { Boczonadi V, Bansagi B, Horvath R. Reversible infantile mitochondrial diseases. J } \\
\text { Inherit Metab Dis } 2015 \text { 38:427-35. }\end{array}$ \\
\hline [21] & $\begin{array}{l}\text { El-Hattab AW, Adesina AM, Jones J et al. MELAS syndrome: clinical manifestations, } \\
\text { pathogenesis and treatment options. Mol Genet Metab 2015;116:4-12. }\end{array}$ \\
\hline$[22]$ & $\begin{array}{l}\text { Rabier D, Diry C, Rotig A, et al. Persistent hypocitrullinaemia as a marker for mtDNA } \\
\text { NARP T } 8993 \text { G mutation? J Inherit Metab Dis 1998;21(3):216-9. }\end{array}$ \\
\hline [23] & $\begin{array}{l}\text { Tiranti V, Briem E, Lamantea E, et al. ETHE1 mutations are specific to ethylmalonic } \\
\text { encephalopathy. J Med Genet 2006;43:340-6. }\end{array}$ \\
\hline$[24]$ & $\begin{array}{l}\text { Peters H, Ferdinandusse S, Ruiter JP, et al. Metabolite studies in HIBCH and ECHS1 } \\
\text { defects: Implications for screening. Mol Genet Metab 2015;115:168-73. }\end{array}$ \\
\hline$[25]$ & $\begin{array}{l}\text { Wortmann SB, Duran M, Anikster Y, et al. Inborn errors of metabolism with 3- } \\
\text { methylglutaconic aciduria as discriminative feature: proper classification and } \\
\text { nomenclature. J Inherit Metab Dis 2013;36:923-8. }\end{array}$ \\
\hline$[26]$ & $\begin{array}{l}\text { Ostergaard E, Hansen FJ, Sorensen N et al. Mitochondrial encephalomyopathy with } \\
\text { elevated methylmalonic acid is caused by SUCLA2 mutations. Brain 2007;130:853- } \\
61 .\end{array}$ \\
\hline$[27]$ & $\begin{array}{l}\text { Lehtonen JM, Forsström S, Bottani E, et al. FGF21 is a biomarker for mitochondrial } \\
\text { translation and mtDNA maintenance disorders. Neurology } 2016 \text { 29;87:2290-2299. }\end{array}$ \\
\hline [28] & $\begin{array}{l}\text { Yatsuga S, Fujita Y, Ishii A, et al. Growth differentiation factor } 15 \text { as a useful } \\
\text { biomarker for mitochondrial disorders. Ann Neurol 2015;78:814-23. }\end{array}$ \\
\hline [29] & $\begin{array}{l}\text { Alston CL, Davison JE, Meloni F, et al. Recessive germline SDHA and SDHB mutations } \\
\text { causing leukodystrophy and isolated mitochondrial complex II deficiency. J Med } \\
\text { Genet 2012;49:569-77. }\end{array}$ \\
\hline$[30]$ & $\begin{array}{l}\text { Scheper GC, van der Klok T, van Andel RJ et al. Mitochondrial aspartyl-tRNA } \\
\text { synthetase deficiency causes leukoencephalopathy with brain stem and spinal cord } \\
\text { involvement and lactate elevation. Nat Genet 2007;39:534-9. }\end{array}$ \\
\hline [31] & $\begin{array}{l}\text { Brown GK, Otero LJ, LeGris M, et al. Pyruvate dehydrogenase deficiency. J Med } \\
\text { Genet 1994;31 875-9. }\end{array}$ \\
\hline [32] & $\begin{array}{l}\text { Alston CL, Rocha MC, Lax NZ, et al. The genetics and pathology of mitochondrial } \\
\text { disease. J Pathol 2017;241:236-250. }\end{array}$ \\
\hline [33] & $\begin{array}{l}\text { Kerr DS. Review of clinical trials for mitochondrial disorders; 1997-2012. } \\
\text { Neurotherapeutics 2013;10:307-319. }\end{array}$ \\
\hline [34] & $\begin{array}{l}\text { Pfeffer G, Majamaa K, Turnbull DM, et al. Treatment for mitochondrial disorders. } \\
\text { Cochrane Database Syst Rev 2012;4: CD004426. }\end{array}$ \\
\hline [35] & $\begin{array}{l}\text { Kanabus M, Heales SJ, Rahman S. Development of pharmacological strategies for } \\
\text { mitochondrial disorders. Br J Pharmacol 2014;171:1798-1817. }\end{array}$ \\
\hline [36] & $\begin{array}{l}\text { Gerards M, van den Bosch BJ, Danhauser K, et al. Riboflavin-responsive oxidative } \\
\text { phosphorylation complex I deficiency caused by defective ACAD9: new function for } \\
\text { an old gene. Brain 2011;134(Pt 1):210-9. }\end{array}$ \\
\hline [37] & $\begin{array}{l}\text { Olsen RK, Koňaříková E, Giancaspero TA, et al. Riboflavin-Responsive and -Non- } \\
\text { responsive Mutations in FAD Synthase Cause Multiple Acyl-CoA Dehydrogenase and } \\
\text { Combined Respiratory-Chain Deficiency. Am J Hum Genet 2016;98(6):1130-45. }\end{array}$ \\
\hline [38] & $\begin{array}{l}\text { Fassone E, Wedatilake Y, Devile CJ, et al. Treatable Leigh-like encephalopathy } \\
\text { presenting in adolescence. BMJ Case Rep 2013:200838. }\end{array}$ \\
\hline [39] & $\begin{array}{l}\text { Haack TB, Klee D, Strom TM et al. Infantile Leigh-like syndrome caused by SLC19A3 } \\
\text { mutations is a treatable disease. Brain 2014;137:e295. }\end{array}$ \\
\hline$[40]$ & $\begin{array}{l}\text { Avula S, Parikh S, Demarest S et al. Treatment of mitochondrial disorders. Curr } \\
\text { Treat Options Neurol 2014;16:292. }\end{array}$ \\
\hline [41] & $\begin{array}{l}\text { Niezgoda J, Morgan PG. Anesthetic considerations in patients with mitochondrial } \\
\text { defects. Paediatr Anaesth 2013;23:785-793. }\end{array}$ \\
\hline [42] & Duberley KE, Heales SJ, Abramov AY, et al. Effect of Coenzyme Q10 \\
\hline
\end{tabular}




\begin{tabular}{|l|l|}
\hline & $\begin{array}{l}\text { supplementation on mitochondrial electron transport chain activity and } \\
\text { mitochondrial oxidative stress in Coenzyme Q10 deficient human neuronal cells. Int } \\
\text { J Biochem Cell Biol 2014;50:60-3. }\end{array}$ \\
\hline$[43]$ & $\begin{array}{l}\text { Enns GM, Kinsman SL, Perlman SL, etal. Initial experience in the treatment of } \\
\text { inherited mitochondrial disease with EPI-743. Mol Genet Metab 2012;105:91-102 }\end{array}$ \\
\hline [44] & $\begin{array}{l}\text { Hughes SD, Kanabus M, Anderson G, et al. The ketogenic diet component decaonoic } \\
\text { acid increases mitochondrial citrate synthase and complex I activity in neuronal } \\
\text { cells. J Neurochem 2014;129:426-433. }\end{array}$ \\
\hline [45] & $\begin{array}{l}\text { Kanabus M, Fassone E, Hughes SD, et al. The pleiotropic effects of decanoic acid } \\
\text { treatment on mitochondrial function in fibroblasts from patients with complex I } \\
\text { deficient Leigh syndrome. J Inherit Metab Dis 2016;39:415-26. }\end{array}$ \\
\hline [46] & $\begin{array}{l}\text { Monteiro JP, Oliveira PJ, Jurado AS. Mitochondrial membrane lipid remodelling in } \\
\text { pathophysiology: a new target for diet and therapeutic interventions. Prog Lipid Res } \\
\text { 2013; 52:513-528. }\end{array}$ \\
\hline [47] & $\begin{array}{l}\text { Cámara Y, González-Vioque E, Scarpelli M, et al. Administration of } \\
\text { deoxyribonucleosides or inhibition of their catabolism as a pharmacological } \\
\text { approach for mitochondrial DNA depletion syndrome. Hum Mol Genet } \\
\text { 2014;23(9):2459-67. }\end{array}$ \\
\hline [48] & $\begin{array}{l}\text { Smeets HJ, Sallevelt SC, Dreesen JC, et al. Preventing the transmission of } \\
\text { mitochondrial DNA disorders using prenatal or preimplantation genetic diagnosis. } \\
\text { Ann N Y Acad Sci 2015;1350:29-36. }\end{array}$ \\
\hline [49] & $\begin{array}{l}\text { Craven L, Herbert M, Murdoch A, et al. Research into Policy: A Brief History of } \\
\text { Mitochondrial Donation. Stem Cells 2016;34(2):265-7. }\end{array}$ \\
\hline
\end{tabular}


Tables

\begin{tabular}{|c|c|}
\hline Central nervous system & $\begin{array}{l}\text { Strokes } \\
\text { Seizures } \\
\text { Neurological/ developmental regression } \\
\text { Neuroradiological features }\end{array}$ \\
\hline Peripheral nervous system & Peripheral neuropathy \\
\hline Eyes & $\begin{array}{l}\text { Ptosis } \\
\text { Ophthalmoplegia } \\
\text { Nystagmus } \\
\text { Visual disturbance } \\
\text { Retinitis pigmentosa }\end{array}$ \\
\hline Hearing & Sensorineural deafness/ hearing impairment \\
\hline Endocrine & $\begin{array}{l}\text { Growth hormone deficiency } \\
\text { Thyroid or parathyroid dysfunction } \\
\text { Multiple hormonal deficiencies }\end{array}$ \\
\hline Pancreatic & $\begin{array}{l}\text { Diabetes mellitus } \\
\text { Exocrine insufficiency }\end{array}$ \\
\hline Hepatic & Liver failure \\
\hline Gastrointestinal & Enteropathy, dysmotility, pseudo-obstruction \\
\hline Muscular & Myopathy \\
\hline Haematological & $\begin{array}{l}\text { Anaemia } \\
\text { Marrow failure }\end{array}$ \\
\hline Renal & $\begin{array}{l}\text { Tubular dysfunction } \\
\text { Progressive renal impairment } \\
\text { Steroid-resistant nephrotic (primary coenzyme } Q_{10} \text { deficiency) }\end{array}$ \\
\hline Cardiac & $\begin{array}{l}\text { Conduction defects } \\
\text { Cardiomyopathy }\end{array}$ \\
\hline Dermatological & $\begin{array}{l}\text { Hypertrichosis } \\
\text { Pili torti (some complex III assembly defects) }\end{array}$ \\
\hline
\end{tabular}




\begin{tabular}{|l|l|}
\hline Table 2: Multi-system evaluation & $\begin{array}{l}\text { Neuroimaging: MRI, CT for acute stroke episodes } \\
\text { Electroencephalogram (EEG) }\end{array}$ \\
\hline Central nervous system & Nerve conduction studies, electromyography \\
\hline Peripheral nervous system & $\begin{array}{l}\text { Ophthalmological referral } \\
\text { Visual evoked potentials/ electroretinogram }\end{array}$ \\
\hline Eyes & $\begin{array}{l}\text { Audiological assessment } \\
\text { Speech and language evaluation }\end{array}$ \\
\hline Hearing & $\begin{array}{l}\text { Growth parameters } \\
\text { Hormone assays (growth hormone, thyroid, parathyroid, } \\
\text { adrenal function) }\end{array}$ \\
\hline Pancreatic & $\begin{array}{l}\text { Blood glucose monitoring, HbA1c } \\
\text { Faecal elastase (exocrine function) } \\
\text { Amylase, lipase }\end{array}$ \\
\hline Hepatic & $\begin{array}{l}\text { Hepatic ultrasound } \\
\text { Liver function tests }\end{array}$ \\
\hline Gastrointestinal & $\begin{array}{l}\text { Assessment of swallow } \\
\text { Growth monitoring }\end{array}$ \\
\hline Muscular & Physiotherapy evaluation \\
\hline Haematological & Full blood count and film \\
\hline Renal & $\begin{array}{l}\text { Tubular function assays (urine NAG/creatinine and } \\
\text { RBP/creatinine) } \\
\text { Renal function tests }\end{array}$ \\
\hline Cardiac & $\begin{array}{l}\text { ECG } \\
\text { Echocardiogram }\end{array}$ \\
\hline
\end{tabular}




\begin{tabular}{|c|c|c|}
\hline System & Feature & Treatment \\
\hline \multirow{3}{*}{$\begin{array}{l}\text { Central nervous } \\
\text { system }\end{array}$} & Seizures & Anticonvulsants \\
\hline & $\begin{array}{l}\text { Stroke-like episodes } \\
\text { (MELAS) }\end{array}$ & Arginine \\
\hline & Dysphagia & SALT intervention, gastrostomy \\
\hline Eyes & $\begin{array}{l}\text { Ptosis } \\
\text { Visual dysfunction }\end{array}$ & $\begin{array}{l}\text { Brow suspension } \\
\text { Visual aids }\end{array}$ \\
\hline Hearing & Hearing impairment & Hearing aids, cochlear implant \\
\hline Endocrine & Hormone deficiency & Appropriate hormone supplementation \\
\hline Pancreatic & $\begin{array}{l}\text { Diabetes } \\
\text { Pancreatic exocrine } \\
\text { insufficiency }\end{array}$ & $\begin{array}{l}\text { Insulin or oral antidiabetic agents } \\
\text { Enzyme supplementation }\end{array}$ \\
\hline Hepatic & $\begin{array}{l}\text { Liver dysfunction, } \\
\text { failure }\end{array}$ & $\begin{array}{l}\text { Consider hepatic transplant if isolated liver } \\
\text { disease }\end{array}$ \\
\hline Gastrointestinal & $\begin{array}{l}\text { Dysmotility, swallow } \\
\text { dysfunction }\end{array}$ & $\begin{array}{l}\text { Gastrostomy } \\
\text { Enteral feeds } \\
\text { Consider parenteral nutrition }\end{array}$ \\
\hline Muscular & Myopathy & $\begin{array}{l}\text { Physiotherapy, appropriate mobility aids and } \\
\text { supports }\end{array}$ \\
\hline Haematological & Anaemia & $\begin{array}{l}\text { Transfusion } \\
\text { Iron/ haematinics }\end{array}$ \\
\hline Renal & Tubular dysfunction & $\begin{array}{l}\text { Electrolyte supplementation } \\
\text { Consider renal replacement therapy }\end{array}$ \\
\hline Cardiac & $\begin{array}{l}\text { Conduction anomalies } \\
\text { Cardiomyopathy }\end{array}$ & $\begin{array}{l}\text { Pacing, Implantable defibrillator } \\
\text { Medical treatment (Lisinopril, beta blockers) } \\
\text { Consider cardiac transplant }\end{array}$ \\
\hline
\end{tabular}




\section{Figures}

Figure 1 A: Nuclear genes associated with mitochondrial disease (Adapted from [5])

\section{OXPHOS structural subunits}

\section{Complex I}

NDUFS1 NDUFS2 NDUFS3

NDUFS4 NDUFS6 NDUFS7

NDUFS8 NDUFV1 NDUFV2

NDUFA1 NDUFA2 NDUFA9

NDUFA10 NDUFA11 NDUFA12

NDUFA13 NDUFB3 NDUFB9

NDUFB11

Complex II

SDHA SDHB SDHCSDHD

Complex III

UQCRB UQCRQ CYC1 UQCRC2

Complex IV

COX4I2 COX6A1 COX6B1 COX7B

COX8A NDUFA4

Complex $V$

ATP5E ATP5A1

Membrane function, lipid

metabolism, dynamics, import

TAZ AGK SERAC1 MFN2 OPA1 GDAP1

DNM1L MFF STAT2 YME1L AIFM1

TIMM8A TIMM5O DNAJC19 GFER

SLC25A3 SLC25A4 SLC25A12 SLC25A13

SLC25A19 SLC25A22 SLC25A25

SLC25A26 SLC25A32 SLC25A40

SLC25A42 SLC25A46 MICU1 QIL1

MPC1

Inhibitors

ETHE1 HIBCH ECHS1 TXN2

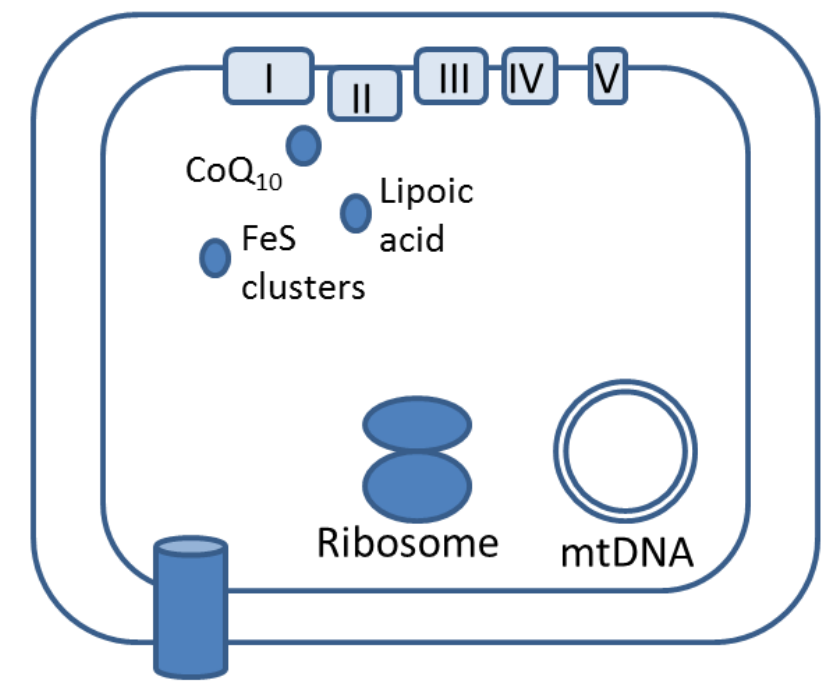

Cofactor biosynthesis PDSS1 PDSS2 COQ2 ADCK3 ADCK4 COQ4 COQ6 COQ7 COQ9 BOLA3 LIAS LIPT1 GLRX5 IBA57

ISCU ISCA2 FXN FDX1L NFU1 ABCB7 SFXN4 LYRM4 NFS1 TPK1 MECR FLAD1 NADK2 NAXE

Mitochondrial translation ELAC2 PUS1 MTO1 TRMU GTPBP3 TRIT1 TRMT5 TRMT10C HSD17B10 NSUN3 TRNT1 PNPT1 MRPS7 MRPS16 MRPS22 MRPS23 MRPL3 MRPL12 MRPL44 GFM1 GFM2 TSFM TUFM AARS2 CARS2 DARS2 EARS2 FARS2 HARS2 IARS2 LARS2 MARS2 NARS2 PARS RARS2 SARS2 TARS2 VARS2 YARS2 QRSL1 GARS KARS MTFMT MTPAP LRPPRC TACO1 C12orf65 RMND1

\section{OXPHOS assembly factors} Complex I

NDUFAF1 NDUFAF2 NDUFAF3

NDUFAF4 NDUFAF5 NDUFAFG

FOXRED1 ACAD 9 NUBPL

TMEM126B

Complex II

SDHAF1 SDHAF2

Complex III

BCS1L HCCS TTC19 UQCC2

LYRM7

Complex IV

SURF1 SCO1 SCO2 COX10 COX14

COX15 COX20 COA5 COA6 COA7

FASTKD2 PET100 CEP89

Complex V

ATPAF2 TMEM70

\section{mtDNA maintenance}

POLG POLG2 TWNK TYMP

DGUOK TK2 RRM2B SUCLA2

SUCLG1 MPV17 FBXL4 DNA2

MGME1 ABAT RNASEH1

SAMHD1

\section{Others}

TMEM126A SPG7 HSPD1 AFG3L2

TRAP1 DARS LARS NNT POP1

APOPT1 CLPB CLPP LONP1

CHCHD10OPA3 
Figure 1 B: Mitochondrial DNA (mtDNA) genes, all associated with mitochondrial disease.

$\begin{array}{lll}\text { Complex I subunits } & \\ M T-N D 1 & M T-N D 5 & \\ M T-N D 2 & M T-N D 6 & \text { Complex III subunit } \\ M T-N D 3 & M T-N D 4 L & M T-C Y B \\ M T-N D 4 & & \end{array}$

Complex IV subunits MT-CO1

MT-CO2

$\mathrm{MT}-\mathrm{CO} 3$

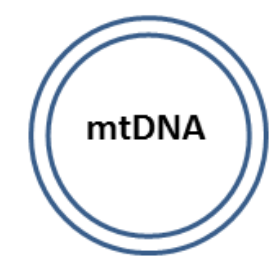

Complex V subunits

MT-ATP6

MT-ATP8

Ribosomal RNA genes

$M T-R N R 1$

$M T-R N R 2$
Transfer RNA genes

MT-TF MT-TW MT-TD MT-TL2

MT-TV MT-TA MT-TK MT-TE

MT-TL1 MT-TN MT-TG MT-TT

MT-TI MT-TC MT-TR MT-TP

MT-TQ MT-TY MT-TH

MT-TM MT-TS1 MT-TS2 
Figure 2: Neuroradiological features in mitochondrial diseases.

A: Axial T2-weighted MRI image from infant with complex I deficiency due to NDUFV2 mutations showing widespread symmetrical increased white matter signal (leukodystrophy) (arrow)

B: Axial T2-weighted MRI image from infant with Leigh disease due to mtDNA MT-ND3 mutation, showing increased signal in basal ganglia (arrow) and thalami (arrowhead)

C: Axial CT scan from child with MELAS syndrome showing acute left parieto-occipital infarct with signal hypointensity (arrows).

D: Axial T2-weighted MRI image from same child as (C), obtained several months after acute insult, showing cortical/subcortical volume loss in infarcted region (arrow), ventriculomegaly, and also abnormal striatum (arrowhead). 


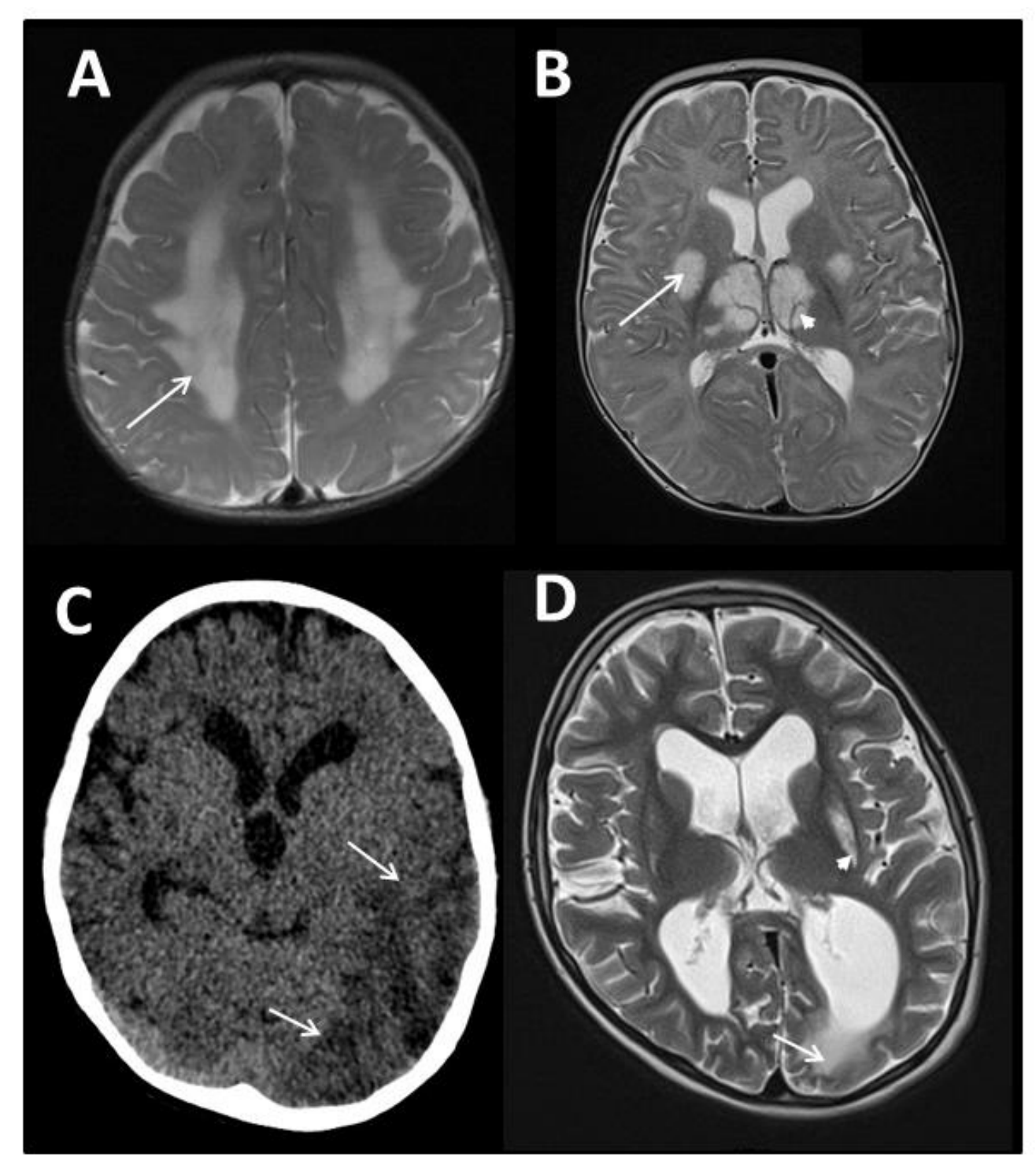

